\title{
Acute eye irritation study of a mixture of glyphosate isopropylamine salt and 2,4 D-isopropylamine
}

\author{
F.D. Suyatna*, S. Darmayanti**
}

\begin{abstract}
Abstrak
Penelitian ini adalah suatu studi iritasi akut pada mata kelinci oleh kombinasi herbisida 240 g/l glifosat isopropilamin dan 120 g/l 2,4 D-isopropilamin. Metode yang digunakan merujuk pada metode yang diusulkan oleh United States Environmental Protection Agency (EPA). Hasil penelitian ini menunjukkan bahwa kombinasi herbisida tersebut menimbulkan konyungtivitis ringan, kemosis ringan, keluarnya sekret mata dan cedera kornea. Perubahan pada mata tersebut bersifat sementara. (Med J Indones 2003; 12: 135-41)
\end{abstract}

\begin{abstract}
This is an acute irritation study of the eye of a mixture of herbicides containing $240 \mathrm{~g} / \mathrm{l}$ of glyphosate isopropylamine and 2,4 Disopropylamine in the rabbits. This study was conducted according the methods as dercribed by the United States Environmental Protection Agency (EPA). Our results show that the combination of the herbicides causes mild conjunctivitis, mild chemosis, eye discharge and corneal injury. The ocular alteration, however, was reversible in nature. (Med J Indones 2003; 12: 135-41)
\end{abstract}

Keywords : glyphosate isopropylamine, 2,4 D-isopropylamine, acute eye irritation study, the United States Environmental Protection Agency (EPA).

With the increasing amount and types of chemicals produced by the manufacturers each year, there is also an increased risk to get toxic exposures. While local exposure may result in skin damage, mild injury may be ignored or could be managed by optimal measures available. On the other hand, eye injury may cause permanent loss of sight and therefore requires critical examination. There are several methods available in studying the toxic effects of a chemical to the eye. However, the method as proposed by the Environment Protection Agency (EPA) could be regarded as the widely accepted one. The purpose of this study is to apply the method in assessing the iritative effect on the eye of a mixture of glyphosate isopropylamine salt and 2,4 D-isopropylamine, which is frequently used in plantation and agricultural activities.

\footnotetext{
* Department of Pharmacology and Therapeutics, Faculty of Medicine, University of Indonesia, Jakarta, Indonesia

** The Jakarta Eye Center, Jakarta, Indonesia
}

\section{METHODS}

The study was conducted according to the Environment Protection Agency (EPA) as described in Health Effect Test Guidelines OPPTS 870.2400 Acute Eye Irritation. ${ }^{1}$ The test material was a mixture of $240 \mathrm{~g} / \mathrm{l}$ glyphosate isopropylamine salt and $120 \mathrm{~g} / \mathrm{l}$ of 2,4 D-isopropylamine ( $\mathrm{pH}: 6.1)$. The animal used in the study was albino rabbit of New Zealand White strain purchased from the Biomedical Laboratory, Directorate General Drug and Food Regulation, Jl. Percetakan Negara, POM, Jakarta, Indonesia.

The animals were individually housed in suspended steel cages with wire mesh bottoms, fed with standard laboratory chow ad libitum. Before the commencement of the study, the animals underwent an acclimatization period of 7 days in the animal house of the Department of Pharmacology, Medical Faculty, University of Indonesia. Eye assessments were carried out at the Jakarta Eye Center, Jl. Cik DItiro 46, Jakarta 10310, Indonesia. 


\section{PROCEDURE OF THE TEST}

Twenty-four hours before the application of the test material, both eyes of all animals were examined with fluorescein using a slit lamp apparatus (INAMI, Tokyo, Japan). Animals showing ocular defects, or preexisting corneal injury were excluded.

On the test day, the test material was preliminarily instilled into the conjunctival sac of one rabbit without local anesthetic. Since the animal showed painful experience and closed its eye, in the actual study the rabbit eyes were anesthetized by one drop of $0.5 \%$ of tetracaine hydrochloride prior to instillation of the test material.

An amount of $0.1 \mathrm{ml}$ of the test material was placed in the conjunctival sac of the left eye of each animal after gently pulling the lower lid away from the eyeball.

The lids were then gently held together for about $1 \mathrm{sec}$ to limit loss of material. The right eye, which remains untreated, served as a control. The eyes were not washed out for 24 hours following instillation of the test substance.

Since in the preliminary study, the test material appeared to give painful sensation, additional testing was performed using animals with eyes washed soon after instillation of the test material. In this case half a minute after instillation of the test material, the eyes of the animals were washed with $5 \mathrm{ml}$ of water for 30 $\mathrm{sec}$ in a slow flow rate so that not to cause injury.

There were 6 rabbits which eyes were not washed and 3 rabbits which eyes were washed after $30 \mathrm{sec}$ instillation. The eyes were examined at 1 hour, 24 hours, 48 hours and 72 hours after instillation. Extended observations were performed on days 4, 7, 8,9 and 14 .

The ocular reaction was recorded and graded as described in Table 1.

Table 1. Evaluation of Ocular Reaction

\begin{tabular}{ll}
\hline \multicolumn{1}{c}{ Grades for Ocular Lesions } & \\
\hline Cornea & 0 \\
Opacity : Degree of density (area most dense taken for reading). & $* 1$ \\
No ulceration or opacity & $* 2$ \\
Scattered of diffuse areas of opacity (other than slight dulling of normal luster), \\
$\quad$ details of iris clearly visible & $* 3$ \\
Easily discernible translucent area, details of iris slightly obscured & $* 4$ \\
Nacrous area, no details or iris visible, size of pupil barely discernible & \\
Opaque cornea, iris not discernible through the opacity & 0 \\
\hline Iris & $* 1$ \\
Normal & \\
Markedly deepened rugae, congestion, sweelling moderate circumcorneal & $* 2$ \\
$\quad$ hyperemia, or injection, any of these or combination of any thereof, & \\
iris still reacting to light (sluggish reaction is positive) & \\
No reaction to light, hemorrhage, gross destruction (any or all of these) & 0 \\
\hline Conjunctiva & 1 \\
Redness (refers to palpebral and bulbar conjunctivae, excluding cornea and iris) & $* 2$ \\
Blood vessels normal & $* 3$ \\
Some blood vessels definitely hyperemic (injected) \\
Diffuse, crimson color, individual vessels not easily discernible \\
Difuse beefy red & $* 4$ \\
Chemosis (refers to lids and/or nictitating membranes) & \\
No swelling & \\
Any swelling above normal (includes nictitating membranes) & 1 \\
Obvious swelling with partial eversion of lids & \\
Swelling with lids about half-closed & \\
Swelling with lids more than half-closed & \\
& \\
\hline
\end{tabular}

* Starred figures indicate positive grades 


\section{RESULTS}

During study period the animals' behaviour and weight, which may reflect systemic effect of the eye irritant were recorded. There was no abnormal behaviour of the animals noted during observation period. As can be seen from Table 2, normal increments of body weight were shown by all rabbits.

Examination of both eyes the rabbits before instillation of a mixture of glyphosate isopropylamine salt and 2,4 d-isopropylamine with fluorescein shows normal condition. There was no retention of fluorescein, or any sign of opacity. The iris was normal, there was no congestion or injection and reaction to light was normal. The conjunctiva looked normal red, there was no injection, chemosis or discharge.

In the preliminary trial, instillation of one drop of the test material without prior administration of the anesthetic agent caused immediate closure of the test eye, suggesting of painful sensation. The eye lids of the test eye became hyperemic. The rabbit became restless and rebellious on handling. When a drop of $0.5 \%$ of tetracaine hydrochloride, was immediately instilled into the test eye, the rabbit resumed its normal behavior again.

Since then, the data collected were from the eyes that were anesthetized prior to application of the test material.

Table 3 shows the result of eyes recorded at 1 hour after instillation of the test material on the lefteye. The right eye, which remains untreated, served as a control. Rabbits no. 1-6, were those which eyes were not washed after instillation and, rabbits no. 7-9 were those which were.

Table 2. Body weight of the rabbit

\begin{tabular}{|c|c|c|c|c|c|c|c|c|c|c|c|c|c|c|c|}
\hline \multirow{3}{*}{$\begin{array}{c}\text { Rabbit } \\
\text { No. }\end{array}$} & \multirow{3}{*}{ Sex } & \multicolumn{14}{|c|}{ Body weight $(\mathrm{kg})$} \\
\hline & & \multicolumn{14}{|c|}{ Day } \\
\hline & & 1 & 2 & 3 & 4 & 5 & 6 & 7 & 8 & 9 & 10 & 11 & 12 & 13 & 14 \\
\hline 1. & Female & 2.20 & 2.20 & 2.20 & 2.25 & 2.25 & 2.30 & 2.30 & 2.30 & 2.35 & 2.35 & 2.40 & 2.40 & 2.40 & 2.50 \\
\hline 2. & Female & 2.15 & 2.15 & 2.15 & 2.20 & 2.20 & 2.25 & 2.25 & 2.25 & 2.30 & 2.30 & 2.30 & 2.35 & 2.35 & 2.35 \\
\hline 3. & Female & 2.25 & 2.25 & 2.25 & 2.30 & 2.30 & 2.30 & 2.35 & 2.35 & 2.40 & 2.40 & 2.45 & 2.45 & 2.50 & 2.50 \\
\hline 4. & Female & 2.00 & 2.00 & 2.00 & 2.10 & 2.10 & 2.15 & 2.15 & 2.20 & 2.20 & 2.20 & 2.25 & 2.25 & 2.25 & 2.25 \\
\hline 5. & Female & 1.75 & 1.75 & 1.80 & 1.80 & 1.80 & 2.00 & 2.00 & 2.00 & 2.10 & 2.10 & 2.10 & 2.15 & 2.15 & 2.20 \\
\hline 6. & Female & 2.00 & 2.00 & 2.00 & 2.10 & 2.10 & 2.15 & 2.15 & 2.20 & 2.20 & 2.20 & 2.25 & 2.35 & 2.35 & 2.40 \\
\hline 7. & Female & 2.25 & 2.25 & 2.25 & 2.30 & 2.30 & 2.40 & 2.40 & 2.40 & 2.45 & 2.50 & 2.50 & 2.50 & 2.60 & 2.60 \\
\hline 8. & Female & 1.80 & 1.80 & 1.80 & 1.90 & 1.90 & 2.00 & 2.00 & 2.00 & 2.10 & 2.10 & 2.15 & 2.15 & 2.20 & 2.20 \\
\hline 9. & Female & 1.90 & 1.95 & 1.95 & 2.00 & 2.00 & 2.10 & 2.10 & 2.15 & 2.15 & 2.20 & 2.25 & 2.25 & 2.25 & 2.30 \\
\hline
\end{tabular}

Table 3. Ocular response at 1 hour instillation of a mixture of glyphosate isopropylamine salt and 2,4 d-isopropylamine

\begin{tabular}{|c|c|c|c|c|c|c|c|c|c|c|}
\hline \multirow{4}{*}{$\begin{array}{c}\text { Rabbit } \\
\text { No. }\end{array}$} & \multicolumn{10}{|c|}{ Grade of injury } \\
\hline & \multirow{2}{*}{\multicolumn{2}{|c|}{ Cornea }} & \multirow{2}{*}{\multicolumn{2}{|c|}{ Iris }} & \multicolumn{6}{|c|}{ Conjunctiva } \\
\hline & & & & & \multicolumn{2}{|c|}{ Redness } & \multicolumn{2}{|c|}{ Chemosis } & \multicolumn{2}{|c|}{ Discharge } \\
\hline & Right & Left & Right & Left & Right & Left & Right & Left & Right & Left \\
\hline 1. & 0 & 2 & 0 & 0 & 0 & 1 & 0 & 1 & 0 & 2 \\
\hline 2. & 0 & 2 & 0 & 0 & 0 & 1 & 0 & 1 & 0 & 2 \\
\hline 3. & 0 & 1 & 0 & 0 & 0 & 1 & 0 & 1 & 0 & 2 \\
\hline 4. & 0 & 1 & 0 & 0 & 0 & 1 & 0 & 1 & 0 & 2 \\
\hline 5. & 0 & 1 & 0 & 0 & 0 & 1 & 0 & 1 & 0 & 2 \\
\hline 6. & 0 & 2 & 0 & 0 & 0 & 1 & 0 & 1 & 0 & 2 \\
\hline 7. & 0 & 1 & 0 & 0 & 0 & 1 & 0 & 1 & 0 & 2 \\
\hline 8. & 0 & 1 & 0 & 0 & 0 & 1 & 0 & 1 & 0 & 2 \\
\hline 9 & 0 & 1 & 0 & 0 & 0 & 1 & 0 & 1 & 0 & 2 \\
\hline
\end{tabular}


One hour after instillation of the test material all the rabbits' left eyes showed corneal and conjunctival alterations. The corneae of rabbits no. 1-6 which were not washed after instillations of a mixture of glyphosate isopropylamine salt and 2,4 d-isopropylamine became cloudy. In some rabbits (No. 1, 2 and 6) the corneal opacity was severer than just diffuse appearance, in which detail of iris was slightly obscured.

The iris, however, was normal in all rabbits. The conjunctivae of all rabbits were unequivocally injected above normal (grade 1), swollen (grade 1) with discharge moistening the lids and hairs just adjacent to lids (grade 2).

In rabbits which eyes were washed after instillation of the test material, the corneae were partly stained with fluorescein. The three rabbits showed hyperemic conjunctivae (grade 1) and chemosis (grade 1). As in unwashed rabbits the iris was normal. Blepharospasm of the test eyes was practically encountered in all rabbits (No. 1-9).

Twenty four hours after instillation of a mixture of glyphosate isopropylamine salt and 2,4 disopropylamine gave different results (Table 4).

Overall diminished reaction of the left eyes of the rabbits was observed at 24 hours after instillation of a mixture of glyphosate isopropylamine salt and 2,4 disopropylamine. Corneal opacity as revealed by fluorescein retention was becoming less severe. Significant improvement was seen in rabbits No. 5, 6, and 8 , in which the grade of ocular injury clearly decreased. Although opacities were still at grade 2 in rabbits 1 and 2, the area of cloudy cornea were smaller in comparison with the data observed at 1 hour after instillation. In rabbit no. 1 the corneal opacity occupied $2 / 3$ of the area at the lower part, whereas in rabbit no. 2 , fluorescein stain occupied $1 / 2$ of the area at the upper part. In concordance with the data on cornea, significant improvement was seen as the absence of conjunctival injury in all rabbits. Discharges of the test eyes were still observed which were ranked 2 in grade.

In comparison with the data obtained at 24 hours (see Table 4), further improvements were observed in corneal injury at 48 hours after instillation of a mixture of glyphosate isopropylamine salt and 2,4 disopropylamine. The left eyes of rabbits no. 3, 4 were completely cleared of fluorescein stain. The degree of corneal injury in rabbits 1, 2 was grade 2. However, the affected area was even smaller than that observed at 24 hours. Similar patterns of improvements were also observed in the corneae of rabbits No. 6, 7 and 9, in which the affected area was either smaller or less opaque if compared with that at 24 hours observation. Conjunctivae in several rabbits, however, were slightly hyperemic. Discharge of the test eyes was still noted, albeit significantly less than that at 24 hours observation.

At 72 hours observation after instillation of a mixture of glyphosate isopropylamine salt and 2,4 disopropylamine, the corneal injury of rabbits No. 1, 2, 6 and 9 was further decreased in comparison with that at 48 hours. It should be noted that, although the gradation of corneal injury remained unchanged, the fluorescein stained area were significantly smaller than that at 48 hours. In rabbit no. 1 and 2, the corneal opacities became approximately $1 / 4$ of the area. In rabbit no. 7, the corneal injury was completely healed. Some hyperemic conjunctivae were still observed in rabbits No. 6, 7 and 9. However, degree of discharge was significantly diminished.

Table 4. Ocular response 24 hours after instillation of a mixture of glyphosate isopropylamine salt and 2,4 d-isopropylamine

\begin{tabular}{|c|c|c|c|c|c|c|c|c|c|c|}
\hline \multirow{4}{*}{$\begin{array}{c}\text { Rabbit } \\
\text { No. }\end{array}$} & \multicolumn{10}{|c|}{ Grade of injury } \\
\hline & \multirow{2}{*}{\multicolumn{2}{|c|}{ Cornea }} & \multirow{2}{*}{\multicolumn{2}{|c|}{ Iris }} & \multicolumn{6}{|c|}{ Conjunctiva } \\
\hline & & & & & \multicolumn{2}{|c|}{ Redness } & \multicolumn{2}{|c|}{ Chemosis } & \multicolumn{2}{|c|}{ Discharge } \\
\hline & Right & Left & Right & Left & Right & Left & Right & Left & Right & Left \\
\hline 1. & 0 & 2 & 0 & 0 & 0 & 0 & 0 & 1 & 0 & 2 \\
\hline 2. & 0 & 2 & 0 & 0 & 0 & 0 & 0 & 1 & 0 & 2 \\
\hline 3. & 0 & 1 & 0 & 0 & 0 & 0 & 0 & 1 & 0 & 2 \\
\hline 4. & 0 & 1 & 0 & 0 & 0 & 0 & 0 & 1 & 0 & 2 \\
\hline 5. & 0 & 0 & 0 & 0 & 0 & 0 & 0 & 1 & 0 & 2 \\
\hline 6. & 0 & 1 & 0 & 0 & 0 & 0 & 0 & 1 & 0 & 2 \\
\hline 7. & 0 & 1 & 0 & 0 & 0 & 0 & 0 & 1 & 0 & 2 \\
\hline 8. & 0 & 0 & 0 & 0 & 0 & 0 & 0 & 1 & 0 & 2 \\
\hline 9. & 0 & 1 & 0 & 0 & 0 & 0 & 0 & 1 & 0 & 2 \\
\hline
\end{tabular}


Table 5. Ocular response 7 days after instillation of a mixture of glyphosate isopropylamine salt and 2,4 d-isopropylamine

\begin{tabular}{|c|c|c|c|c|c|c|c|c|c|c|}
\hline \multirow{4}{*}{$\begin{array}{c}\text { Rabbit } \\
\text { No. }\end{array}$} & \multicolumn{10}{|c|}{ Grade of injury } \\
\hline & \multirow{2}{*}{\multicolumn{2}{|c|}{ Cornea }} & \multirow{2}{*}{\multicolumn{2}{|c|}{ Iris }} & \multicolumn{6}{|c|}{ Conjunctiva } \\
\hline & & & & & \multicolumn{2}{|c|}{ Redness } & \multicolumn{2}{|c|}{ Chemosis } & \multicolumn{2}{|c|}{ Discharge } \\
\hline & Right & Left & Right & Left & Right & Left & Right & Left & Right & Left \\
\hline 1. & 0 & 0 & 0 & 0 & 0 & 0 & 0 & 0 & 0 & 1 \\
\hline 2. & 0 & 0 & 0 & 0 & 0 & 0 & 0 & 0 & 0 & 1 \\
\hline 3. & 0 & 0 & 0 & 0 & 0 & 0 & 0 & 0 & 0 & 0 \\
\hline 4. & 0 & 0 & 0 & 0 & 0 & 0 & 0 & 0 & 0 & 0 \\
\hline 5. & 0 & 0 & 0 & 0 & 0 & 0 & 0 & 0 & 0 & 0 \\
\hline 6. & 0 & 1 & 0 & 0 & 0 & 1 & 0 & 0 & 0 & 1 \\
\hline 7. & 0 & 0 & 0 & 0 & 0 & 1 & 0 & 0 & 0 & 1 \\
\hline 8. & 0 & 0 & 0 & 0 & 0 & 0 & 0 & 0 & 0 & 1 \\
\hline 9. & 0 & 0 & 0 & 0 & 0 & 1 & 0 & 0 & 0 & 1 \\
\hline
\end{tabular}

At day 7 of observation, all test eyes except one were completely recovered (Table 5). In rabbit no. 6, the corneal opacity was almost disappeared. There were 2 fluorescein spots in the upper and lower part of the eye occupied about $1 / 10$ of the area. Slight hyperemic reaction was still seen.

Eye examination was continued and at day 9 after instillation of the test material, corneal opacity in rabbit no. 6, and other reaction such as conjunctival and discharge were completely dissapeared. All rabbits remained normal thereafter until the end period of observation (day 14).

\section{DISCUSSION}

2,4 D is 2,4-dichlorphenoxyacetic acid. This chemical is used as herbicide. Although 2,4 D is effective alone against broad - leaved weeds, it is often used in combination with other herbicides. 2,4 D is of only moderate oral toxicity to rodents; the oral LD50 values in rat is $375-1200 \mathrm{mg} / \mathrm{kg} \mathrm{BW}$. It causes mucosal irritation of gastrointestinal tract. However, there is no report on eye.

The second component of the test mixture is glyphosate, which is also used as herbicide. It is a very broad spectrum herbicide with the acute oral $\mathrm{LD}_{50}$ in rats of $5600 \mathrm{mg} / \mathrm{kg} \mathrm{BW}$. According to the report, ${ }^{3}$ glyphosate is slightly irritating to rabbit eye. However, formulations might be slightly more irritating.
Both active chemicals were dissolved in isopropylamine. This third component of herbicides is an alkylamine derivative. Its acute oral $\mathrm{LD}_{50}$ in rats is $820 \mathrm{mg} / \mathrm{kg}$ BW. Reports published ${ }^{4}$ described transient visual disturbances (halos around lights) after exposure to the vapor for 8 hours caused by mild corneal edema. However, the liquid form was reported to be able to cause severe eye burns and permanent visual impairment. Our study found eye damage after single instillation of the combination. Sign of eye irritation was observed when the rabbit's eye was instilled with the test material without prior to local anesthetic administration. Basically the eye injury observed in our study caused by the mixture of herbicide can be explained by the specific damaging effects of acidic solution to the eye. Exposure of epithelial surface of both conjunctiva and cornea to acid results in coagulation of the cells with varying degrees of opacification which will be apparent within seconds after exposure. ${ }^{5}$ In mild form of injury, the affected epithelial cells begin to slough within hours after exposure and will regenerate in several days. Our results revealed that the test material caused mild conjunctival injection, mild chemosis, profuse discharge and reversible corneal injury. These data support the contention that the mixture of herbicide caused mild injury of the eye in the rabbits.

It should be noted, however, that great caution nevertheless should be exercised when handling with these combination. Results of animal tests can not be directly extrapolated to human. It is entirely possible that certain chemical which is not harmful to the eye in animal studies may cause eye damage in human. 
Figure 1. Normal eye

Figure 2. Left eye of rabbit no. 7 one hour after instillation of $240 \mathrm{~g} / \mathrm{l}$ glyphosate isopropylamine - $120 \mathrm{~g} / \mathrm{l}$ 2,4 D isopropylamine. The cornea was partially stained with fluorescein (grade 1), normal iris, hyperemic conjunctiva (grade 1), chemosis (grade 1) and discharge (grade 2). 
Figure 3. Left eye of rabbit no. 2, 48 hours after instillation of $240 \mathrm{~g} /$ glyphosate isopropylamine - $120 \mathrm{~g} / \mathrm{l}$ 2,4 D isopropylamine. The cornea was partially ed with fluorescein, details of iris behind the affected cornea was slightly obscured (grade 2), normal iris, hyperemic conjunctiva, definitely injected, but individual vessels were easily discernible (grade 1), chemosis, discharge (grade 2).

\section{Acknowledgement}

We are very thankful to Dr. Darwan Purba, Sp.M for his generousity enabling us to use the equipments and work in the Jakarta Eye Center and Dr. T. Gondhowiarjo, Ph.D, Sp.M for his support.

\section{REFERENCES}

1. Health Effect Test Guidelines OPPTS 870.2400. Acute Eye Irritation. United States Environmental Protection Agency (EPA) (August 1998).
2. Rowe VK, Hymas TA. Summary of toxicological information on 2,4 D and 2,4,5-T type herbicides and an evaluation of the hazards to livestock associated with their use. Am J Vet Res 1954;15:622-9.

3. Stevens JT, Sumner DD. Herbicides. In: Hayes WJ Jr and Laws ER Jr, editors. Handbook of Pesticide Toxicology Vol.3. Academic Press Inc: 1991. p. 1339-40.

4. Windholz M, Budavari S, Blumetti R, Otterbein E, editors. The Merck Index, 10 ${ }^{\text {th }}$ ed, Merck \& Co: 1983.

5. Moore T, Mc Culley J. Chemical injuries of the eye. In : Leibowits HM, editors. Corneal disorders. WB Saunders Co: 1984. p. $488-97$. 